\title{
Prolapsed lumbar disc in a nine years old girl: a case report
}

\author{
Walid A. Abdel Ghany ${ }^{1}$, Mohamed A. Nada ${ }^{1 *}$ (D), George Halim ${ }^{1}$ and Iman H. Hewedi
}

\begin{abstract}
Lumbar disc prolapse has been rarely described in young children. In this report, we reported a lumbar disc prolapse in an overweight 9-year-old girl after trauma. The girl had a severe radicular pain that did not respond to conservative treatment. Operative management was conducted, and histopathologic examination of the prolapsed disc material revealed chondrocyte proliferation, tears and clefts of the annulus fibrosus, and fibrocartilaginous degeneration. These early degenerative changes suggested the effect of the high body mass index as an underlying factor for the disc prolapse in this girl.
\end{abstract}

Keywords: Back pain, Pediatric disc prolapse, Pediatric spine, Traumatic disc prolapse

\section{Background}

Prolapsed lumbar disc (PLD) is a common spine disorder that is frequently encountered in the adult population, and it commonly occurs as a result of either trauma or, more frequently, disc degeneration [1-3].

On the other hand, PLD has been rarely described in young children, with only eight cases in the literature reported under the age of 9 years, the youngest being 1 year [1-8].

Unlike adults where degenerative changes are the main cause, the main factor associated with PLD in children is trauma with subsequent axial load or a sport-related injury. Trauma accounts for about $70 \%$ of the cases, whereas genetic anomalies, growth spurts, weight gain, and nutritional factors are believed to account for the remainder [5, 7-10].

Less than $10 \%$ of low back pain pediatric patients are due to disc herniation; however, less than half of these require surgery [11]. Due to the rarity of lumbar disc pathology and the lack of classical radiculopathy in the pediatric population, there is often a delay in diagnosis [12].

Symptoms of PLD in children include low back pain and radiculopathy. Disc herniation in toddlers who cannot yet express their pain is manifested by difficulties in

\footnotetext{
* Correspondence: Mohamednada_md@hotmail.com

${ }^{1}$ Department of Neurological Surgery, Ain Shams University, Cairo, Egypt

Full list of author information is available at the end of the article
}

walking or a total refusal to stand, walk, or crawl associated with irritability $[1,8]$.

The physical examination of a child with a suspected PLD can be useful. Children with PLD have a greater limitation of movement than adults. And most of them have a positive straight leg raising (SLR) and crossed SLR signs $[5,13,14]$.

The differential diagnosis of back pain and/or radiculopathy in young children includes discitis, vertebral osteomyelitis, and neoplasms, which occur more frequently in children below 10 years of age, as well as spondylolysis, spondylolisthesis, Schmorl's nodules (Scheuermann's kyphosis), and slipped epiphysis, which are more frequently described in children older than 10 years of age [14].

Plain radiographs may reveal no abnormality in the majority of children with PLD. However, these radiographs must be obtained because they help in diagnosing or ruling out other disorders of the lumbar spine such as pars defects (spondylolysis and spondylolisthesis) [15]. The investigative of choice would be a magnetic resonance imaging (MRI). This is useful not only to diagnose a suspected herniated lumbar disc, but also allows for the investigation of alternate pathologies, such as an epidural hematoma, fractures, and other nonsurgical pathologies [5].

Initially, the management of PLD in children consists of conservative treatment comprising bed rest, analgesic 
therapy, and avoiding strenuous physical activities and sports $[1,11]$.

Conservative measures are considered before surgery unless PLD affects the patient's motor and neurological functions such as bowel and bladder dysfunction or causing a truly incapacitating pain. Children are less responsive to conservative treatment than adults, and this is mainly attributed to the viscosity and high elasticity of the intervertebral disc in children compared with that in adults $[16,17]$.

Surgical procedures consisted of unilateral laminotomy for lateralized discs and bilateral laminotomy or laminectomy for central discs, along with microsurgical discectomy in both cases. Removal of PLD in children is usually difficult because of its viscous and slippery consistency. However, the surgical approach should be individualized and the amount of bone removal should be balanced against the risk of developing subsequent spinal deformity in the growing child [15].

It is important to note that neoplastic disease and infection remain as important differentials in this situation and care should be taken to analyze all samples taken intraoperatively [7].

\section{Case report}

A 9-year-old girl, with a height of $115 \mathrm{~cm}$ and a weight of $55 \mathrm{~kg}$, presented to our clinic in January 2017 with low back pain and severe left thigh and leg pain and paresthesia of 2 months duration with a progressive course. The onset of the symptoms was related to a back trauma due to falling on the ground while running in her school. The symptoms were not associated with saddle hypoesthesia or sphincteric abnormality. The patient had intact motor power, and SLR sign was positive at $10^{\circ}$; the patient tried medical conservative treatment for relieving the symptoms in the form of nonsteroidal anti-inflammatory drugs, muscle relaxants, and pregabalin, for a period of 1 month, but all failed.

MRI lumbosacral spine revealed a posterior herniated soft lumbar disc between L5 and S1, compressing the left S1 root (Fig. 1). The patient was prepared for surgery, full laboratory investigations were done, and all showed normal results.

\section{Operative details}

The child underwent a unilateral left interlaminar approach with partial removal of the L5 and sacral laminas under the operating microscope; the disc material was very soft, viscous, slippery, and jelly like, not easily punched and removed in piecemeal [18]. The exiting S1 nerve root was completely decompressed. In addition, samples were taken for pathological examination. There were no intraoperative complications. The child's postoperative recovery was uneventful, and she was subsequently discharged home $48 \mathrm{~h}$ postoperatively with dramatic improvement of sciatic pain.

\section{Pathological examination}

The tissue sample was immediately fixed in $4 \%$ buffered formaldehyde for approximately $12 \mathrm{~h}$ followed by routine processing with paraffin embedding. No obvious calcification or residual bone material was encountered, and hence, decalcification treatment was not applied. Hematoxylin and eosin (H\&E) sections were then examined by light microscopy.

\section{Results}

The disc material comprising of nucleus pulposus and annulus fibrosus exhibited histologic alterations denoting degenerative changes previously described by Boos et al. [19] and Weiler et al. [20], with no evidence of obvious inflammation or neoplastic formation. These histologic alterations include mild chondrocyte proliferation, tears and clefts in the annulus fibrosus, granular change

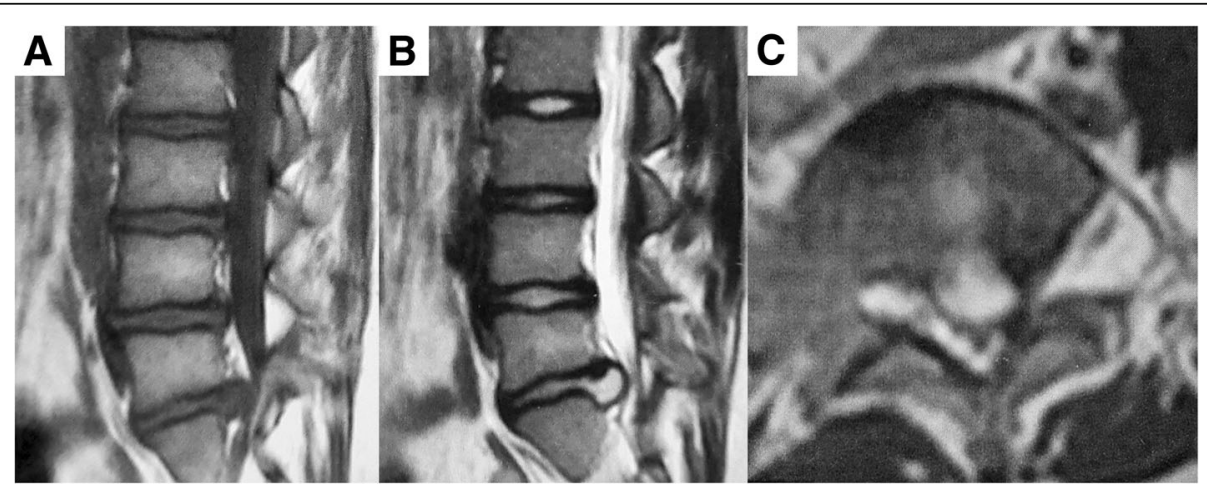

Fig. 1 a Sagittal T1, b sagittal T2, and c axial T2 of the lumbosacral spine showing the protruded disc fragment compressing the left S1 root 
within the fibrocartilage matrix, and subtle mucous degeneration.

Figure 2 represents the histopathologic features of degeneration in the vertebral disc of the 9-year-old patient (all; H\&E stain, original magnification $\times 200$ ).

\section{Postoperative follow-up}

The child came for follow-up visits after 1, 3, 6, and 9 months; she was sciatica free and back to her normal daily activity; MRI lumbosacral spine was done after 6 months and did not show any signs of nerve root compression (Fig. 3).

\section{Discussion}

Prolapsed lumbar disc is a rare disorder in children, and it accounts for about 1-3\% of lumbar disc surgeries, with a higher incidence among Japanese population [21, 22]. However, in most of the reports concerning the pediatric lumbar disc prolapse, they reported children older than 11 years of age. Nerve root symptoms are extremely rare in children younger than 9 years, with only eight cases reported in the literature; all cases reported revealed L4-5 disc herniation except two cases that revealed L5-S1 disc herniation.

In children, usually, there are no degenerative changes. Moreover, the authors suggested that in this young age group, another mechanism could be involved like trauma which can cause disc herniation which may be accompanied by vertebral rim avulsion $[9,17]$.

The body mass index (BMI) of this patient was 41.5, which indicates that she is morbidly obese. Overweight is a predominant factor in the development of lumbar disc disease compared with age and sex [23].

In this report, histopathologic examination of the disc material was performed. Up to our knowledge, we did not find similar data in the literature. The pathologic examination revealed undergoing degeneration of the disc material as described before. This invited an important question: whether this degeneration is a primary pathological process or it occurred secondary to trauma.

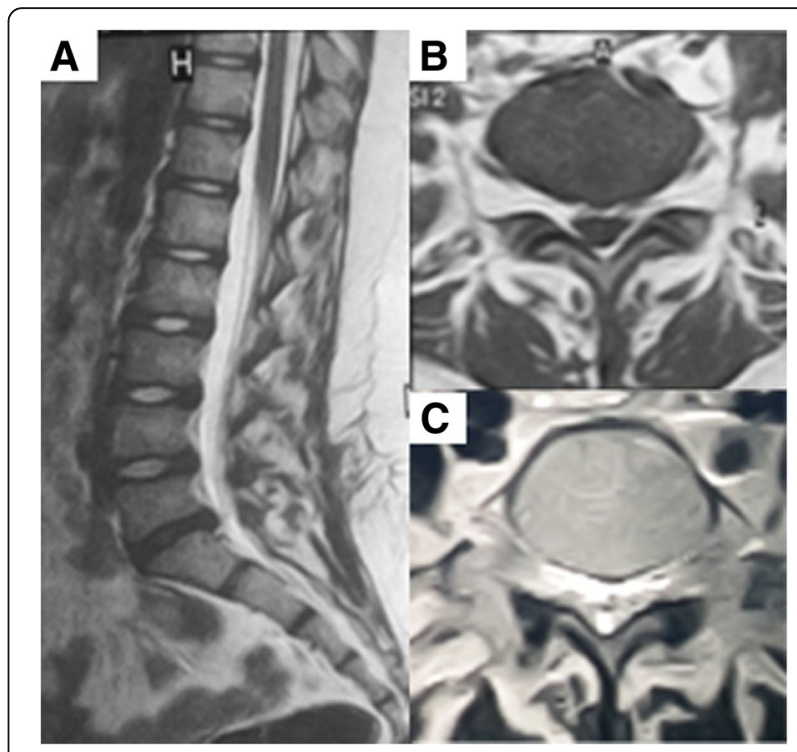

Fig. 3 Postoperative MRI of the lumbosacral spine. a Sagittal T2. b Axial T1. c Axial T2

Like adults, the first line of treatment for children with a prolapsed lumbar disc is the conservative treatment that mainly consists of bed rest and analgesic therapy. Those with intractable pain and/or neurological dysfunction should go for surgical excision of the herniated disc. A minimally invasive approach should be selected to avoid complications of the growing spine of children; a hemilaminectomy or a laminotomy/laminoplasty with microscopic magnification is preferred [15].

\section{Conclusion}

Prolapsed lumbar disc in the pediatric age group is a very rare clinical and pathological condition. Usually, diagnosis is delayed because of the lack of experience with this symptomatology in young children. However, it should be taken into consideration as a differential diagnosis in children complaining of back pain and radiculopathy especially in those with high body mass index and/or history of trauma.

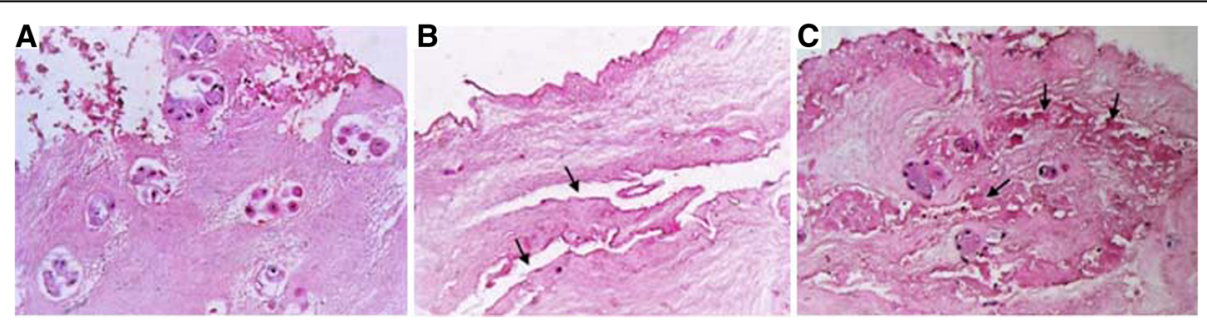

Fig. 2 Hematoxylin and eosin-stained sections (original magnification $\times 200$ ). a Chondrocyte proliferation with multiple chondrocytes growing in sharply demarcated small rounded clusters. b Structural alterations with concentric tears (arrows) following the collagen fiber bundle orientation in the annulus fibrosus. c Granular changes (arrows) with eosinophilic-staining amorphous granules within the fibrocartilage 


\section{Abbreviations}

BMl: Body mass index; H\&E: Hematoxylin and eosin stain; MRI: Magnetic resonance imaging; PLD: Prolapsed lumbar disc; SLR: Straight leg raising

\section{Acknowledgements}

No other person contributed to this article.

\section{Funding}

The patient included in this report was operated under the cover of the Egyptian Health Insurance System. The procedure was done in the Ain Shams University Hospitals.

\section{Availability of data and materials}

Data supporting this case report results is demonstrated in the manuscript.

\section{Authors' contributions}

WAAG contributed to the report conception and design. IHH performed the histopathologic examination. GH contributed to the analysis and interpretation of data. WAAG and MAN drafted the manuscript. WAAG revised the manuscript. All authors read and approved the final manuscript.

\section{Ethics approval and consent to participate}

Not applicable.

\section{Consent for publication}

Written consent to publish was obtained from the patient's parents.

\section{Competing interests}

The authors declare that they have no competing interests.

\section{Publisher's Note}

Springer Nature remains neutral with regard to jurisdictional claims in published maps and institutional affiliations.

\section{Author details}

'Department of Neurological Surgery, Ain Shams University, Cairo, Egypt.

2Department of Pathology, Ain Shams University, Cairo, Egypt.

Received: 2 April 2018 Accepted: 31 March 2019

Published online: 23 April 2019

\section{References}

1. Benifla M, Melamed I, Barrelly R, Aloushin A, Shelef I. Unilateral partial hemilaminectomy for disc removal in a 1-year-old child. J Neurosurg Pediatr. 2008;2(2):133-5.

2. Dang $L$, Liu Z. A review of current treatment for lumbar disc herniation in children and adolescents. Eur Spine J. 2009;19(2):205-14. https://doi.org/10 1007/s00586-009-1202-7.

3. Lavelle WF, Bianco A, Mason R, Betz RR, Albanese SA. Pediatric disk herniation. J Am Acad Orthop Surg. 2011;19(11):649-56.

4. Alexiou GA, Stefanaki K, Sfakianos G, Prodromou N. Lumbar disc herniation in a child with cystic fibrosis: case report. Arch Argent Pediatr. 2014;112(2): e43-5.

5. Cahill J, Frost G, Solanki GA. Paediatric lumbar disc herniation in the very young: a case-based update. Childs Nerv Syst. 2011;27(5):687-91.

6. MacGee EE. Protruded lumbar disc in a 9-year-old boy. J Pediatr. 1968;73(3): 418-9.

7. Martinez-Lage JF, Fernández Cornejo V, Lopez F, Poza M. Lumbar disc herniation in early childhood: case report and literature review. Childs Nerv Syst. 2003;19(4):258-60.

8. Revuelta R, De Juambelz PP, Fernandez B, Flores JA. Lumbar disc herniation in a 27-month-old child. Case report. J Neurosurg Jan. 2000; 92(1 Suppl):98-100.

9. DeOrio JK, Bianco AJ Jr. Lumbar disc excision in children and adolescents. J Bone Joint Surg Am. 1982;64(7):991-6.

10. Fitzer PM. Anterior herniation of the nucleus pulposus: radiologic and clinical features. South Med J. 1985;78(11):1296-300.

11. Durham SR, Sun PP, Sutton LN. Surgically treated lumbar disc disease in the pediatric population: an outcome study. J Neurosurg. 2000;92(1 Suppl):1-6.
12. Martinez-Lage JF, Martinez RA, Lopez F, Poza M. Disc protrusion in the child Particular features and comparison with neoplasms. Childs Nerv Syst. 1997; 13(4):201-7.

13. Kotil K, Akcetin M, Bilge T. Cauda equina compression syndrome in a child due to lumbar disc herniation. Childs Nerv Syst. 2004;20(6):443-4.

14. Sassmannshausen G, Smith BG. Back pain in the young athlete. Clin Sports Med. 2002;21(1):121-32.

15. Haidar R, Ghanem I, Saad S, Uthman I. Lumbar disc herniation in young children. Acta Paediatr. 2010:99(1):19-23.

16. Slotkin JR, Mislow JM, Day AL, Proctor MR. Pediatric disk disease. Neurosurg Clin N Am. 2007:18(4):659-67.

17. Gennuso R, Humphreys RP, Hoffman HJ, Hendrick EB, Drake JM. Lumbar intervertebral disc disease in the pediatric population. Pediatr Neurosurg. 1992;18(5-6):282-6.

18. Shillito J Jr. Pediatric lumbar disc surgery: 20 patients under 15 years of age Surg Neurol. 1996:46(1):14-8.

19. Boos N, Weissbach S, Rohrbach H, Weiler C, Spratt KF, Nerlich AG Classification of age-related changes in lumbar intervertebral discs: 2002 Volvo Award in basic science. Spine (Phila Pa 1976). 2002;27(23):2631-44.

20. Weiler C, Lopez-Ramos M, Mayer HM, Korge A, Siepe CJ, Wuertz K, et al. Histological analysis of surgical lumbar intervertebral disc tissue provides evidence for an association between disc degeneration and increased body mass index. BMC Res Notes. 2011;16(4):497.

21. Huisman TA. Pediatric tumors of the spine. Cancer Imaging. 2009;9 Spec No A(Special issue A):S45-S48. Published 2009 Oct 2. https://doi.org/10.1102/ 1470-7330.2009.9012

22. Kurihara A, Kataoka O. Lumbar disc herniation in children and adolescents. A review of 70 operated cases and their minimum 5-year follow-up studies. Spine (Phila Pa 1976). 1980;5(5):443-51.

23. Xu X, Li X, Wu W. Association between overweight or obesity and lumbar disk diseases: a meta-analysis. J Spinal Disord Tech. 2015:28(10):370-6.

\section{Submit your manuscript to a SpringerOpen ${ }^{\circ}$ journal and benefit from:}

- Convenient online submission

- Rigorous peer review

- Open access: articles freely available online

- High visibility within the field

- Retaining the copyright to your article

Submit your next manuscript at $\boldsymbol{\nabla}$ springeropen.com 